\title{
Apocrine Differentiation
}

National Cancer Institute

\section{Source}

National Cancer Institute. Apocrine Differentiation. NCI Thesaurus. Code C62493.

A morphologic finding that indicates the presence of cells with abundant eosinophilic and granular cytoplasm in a tumor sample. 